En las postrimerias del franquismo, Manuel Fraga Iribarne reexaminó ARTÍCULO $\cdot 87-100$

la normativa para la publicación de libros en España y abrió las puertas a las traducciones al catalán, al gallego y al vasco. Con estos cambios, en 1962 nació en Barcelona Edicions 62, editorial que se centró mayoritariamente en colecciones de narrativa y ensayo traducido. Josep Maria Castellet (1926-2014) fue el director literario de Edicions 62 entre 1964 y 1996. Durante los primeros años de la editorial, algunas de sus colecciones publicaron traducciones de textos ideológicos, entre ellos feministas. Castellet fue el promotor directo de muchas de estas versiones. Por medio de los textos memorialisticos del editor, este artículo quiere reseguir cómo, cuándo y por qué Castellet introdujo estos textos en Cataluña y qué tipo de relación mantuvo con las autoras.

PALABRAS CLAVE: historia de la traducción, traducción y género, traducción y feminismo, censura franquista, Josep Maria Castellet

\title{
Josep Maria Castellet, editor de autoras feministas traducidas $^{\mathrm{I}}$
}

\author{
PILAR GODAYOL \\ Universidad de Vic
}

I Este artículo se enmarca en las actividades del grupo de investigación consolidado «Grupo de Estudios de Género: Traducción, Literatura, Historia y Comunicación» (20I4, SGR 62) de la Universidad de Vic-Universidad Central de Cataluña (UVic-UCC) y del proyecto $\mathrm{I}+\mathrm{D}+\mathrm{i}$ «Traducción y censura: género e ideología (I939-2000)», con el número de referencia FFI2OI4-52989- $\mathrm{C}_{2}-2-\mathrm{P}$, financiado por el Ministerio de Economía y Competitividad. Número ORCID de la autora: 0000-0003-2513-5334. Correo electrónico: pgodayol@uvic.cat.

\section{Josep Maria Castellet, publisher of feminist writers in translation}

Towards the end of the Francoist dictatorship, Manuel Fraga Iribarne revised the criteria for book publication in Spain and made way for translations into Catalan, Galician and Basque. In 1962, as a result of these changes, the publishing house Edicions 62 opened in Barcelona, concentrating its activity mainly on collections of translated narrative and non-fiction. The literary director of Edicions 62 between 1964 and 1996 was Josep Maria Castellet (1926-2014). During the first years of publishing activity, Castellet directly promoted many of the translations of ideological works, including feminist texts, that appeared in various collections. With the help of Castellet's autobiographical writings, this article aims to follow through the process of how, when and why Castellet brought out these texts in Catalonia and how he related to the feminist writers.

KEY WORDS: history of translation, translation and gender, translation and feminism, Francoist censorship, Josep Maria Castellet. 


\section{PRELIMINARES}

Después de la Guerra Civil, el franquismo para- lizó completamente la dinámica de las editoriales españolas. A partir de I938, cualquier texto con intención de ser publicado tuvo que superar los trámites de la censura previa. Durante las dos primeras décadas de la dictadura, las traducciones al catalán, al gallego y al vasco fueron completamente prohibidas. A principios de los años sesenta el nuevo ministro de Información y Turismo designado por Franco, Manuel Fraga Iribarne, revisó los criterios para la edición de libros en España y optó por una cierta «liberalización» de la censura, aprobando en rg66 una nueva Ley de Prensa e Imprenta, la llamada Ley Fraga, que invalidó la anterior. Después de décadas de aridez absoluta, sin versiones de obras extranjeras, la nueva política ministerial abrió las puertas a las traducciones a las distintas lenguas del estado. Fue en estos años que la industria editorial catalana vivió una etapa de pletórico dinamismo. ${ }^{2}$ Con estos cambios, en I962 nació en Barcelona Edicions 62, editorial que se centró mayoritariamente en colecciones de narrativa y ensayo traducido.

Josep Maria Castellet (I926-2014) fue el director literario de Edicions 62 entre r964 y I996. Durante los primeros años de la editorial, algunas de sus colecciones (entre ellas, «Llibres a l'Abast», «El Balancí» o «Biblioteca Bàsica de Cultura Contemporània») publicaron traducciones al catalán de textos ideológicos, entre ellos feministas, obviamente supervisados por el aparato censor del régimen, que, hasta I978,

2 Para conocer la política censora sobre la traducción catalana durante los últimos años del franquismo, se pueden consultar, entre otros, los estudios de Cisquella et al. (1977), Abellán (1980), Vallverdú (1987, 2013), GutiérrezLanza (I997), Llanas (2006, 2007), Cornellà-Detrell (2010) y Bacardí (20I2). obligó a todas las editoriales del país a solicitar el visto bueno por escrito a la Dirección General de Información del Ministerio de Información y Turismo (MIT). A pesar de recorrer, unos más que otros, un largo camino burocrático de censura institucional antes de llegar a las librerías, algunos clásicos de la historia del feminismo llegaron por primera vez a España en catalán durante esta época de expansión y supuesta apertura de ideas. Castellet fue el mecenas/promotor directo de muchas de estas traducciones, como los ensayos de La mistica de la feminitat (1965) (The feminine mystique, I963), de Betty Friedan, y El segon sexe (I968) (Le deuxième sexe, 1949), de Simone de Beauvoir, y la novela $A p a-$ radors per a una dona (I969) (The company she keeps, I962), de Mary McCarthy.

Mediante ensayos y memorias del editor, este artículo quiere abordar cómo y de qué manera Josep Maria Castellet importó estos textos en Cataluña. ¿Por qué decidió traducirlos? ¿Cómo llegó a las autoras? ¿Qué tipo de relación mantuvo con ellas? ¿Quiénes fueron sus cómplices intelectuales? Asimismo, examinaremos el contexto cultural que alimentó, con más o menos dificultades, la publicación de títulos feministas durante los últimos años de la dictadura franquista.

\section{JOSEP MARIA CASTELLET Y EDICIONS 62}

Editor, crítico literario y escritor, Josep Maria Castellet (Barcelona, I926-2014) fue uno de los protagonistas de la historia cultural catalana y española de la segunda mitad del siglo xx. Educado en las instituciones de la época (con paréntesis de temporadas en Londres con la familia), inició su vida intelectual en las revistas universitarias de finales de los años cuarenta. Miembro 
activo de la llamada Escuela de Barcelona, ${ }^{3}$ participó en la elaboración del catálogo inicial de Seix Barral (1954-1967), antes de asumir la dirección literaria de Edicions 62 y Península. Hombre autodidacta abierto a las influencias extranjeras, con importantes contactos con editores nacionales e internacionales, miembro del jurado de los premios de editores y del premio internacional de literatura (fundado por Carlos Barral, con otros grandes editores del momento, como Giulio Einaudi, Gaston Gallimard y Ernst Rowohlt), además de formar parte de la comes (Comunidad Europea de Escritores), Castellet se convirtió en «la ventana al exterior de 62» (2015), según Manuel Llanas. En los años sesenta, cuando la presencia de escritores y editores peninsulares era un hecho desconocido en los foros internacionales, viajó por Europa, participó en reuniones literarias y conoció muchos intelectuales de diferentes países. Consciente de sus privilegios, recordaba:

Entre Barcelona y Madrid, siempre que podía escogía París, Roma, Londres, Ginebra o Milán, ciudades que frecuentaba con la mínima excusa. [...] Yo llegaba de los viajes cargado de libros, para uso propio o para intentar traducciones, muchas veces desautorizadas por la censura. En cualquier caso, las escapadas a la Europa democrática nos enriquecían a todos. Encerrados en España, el vicio de la libertad era un tipo de vicio más o menos solitario. Teniendo en cuenta que cuando no hay represión no hay vicio, las salidas a Europa se convirtieron en modestas orgías de libertad, no solamente toleradas, sino fomentadas por el ambiente y por nues-

3 La Escuela de Barcelona la formaron un grupo de poetas y críticos -entre ellos, Carlos Barral, Jaime Gil de Biedma y José Agustín Goytisolo-, que, a finales de los años cincuenta, se constituyeron como la «generación de los 50", avalados por la famosa antología de Josep Maria Castellet, Veinte años de poesía española (1960). Para más información, véase La Escuela de Barcelona (I988), de Carme Riera. tros compañeros extranjeros. [...] De los amigos y conocidos de aquellos años, publiqué, entre otros, Partolini, Buttor, Calvino, Grass, Robbe-Grillet, Mary McCarthy, Pasolini, etc. (Castellet, I987: 42-44).

Contratado en junio de 1964 por el fundador de Edicions 62, Max Cahner, porque «significaba la modernidad literaria necesaria para la editorial» (Muñoz, 2006: 169), Castellet dejó un buen sueldo en una editorial en expansión de temas jurídicos, Praxis, y empezó a trabajar en una de futuro incierto, pero atractivo y ambicioso. Castellet entró en Edicions 62 con un deber concreto adquirido con Cahner: «él estaba buscando un director literario, pero tenía una urgencia específica y era la de introducir en el mundo de la edición catalana una importante presencia de la literatura extranjera, especialmente la más estrictamente contemporánea» (Castellet, 20I2: 125). Todo esto sin dejar de lado «una insólita ambición, la de acabar construyendo una editorial que alcanzara todos los campos de la cultura, al menos de la humanística», [...] «esta ambición pasaba por todas las corrientes de la literatura: obviamente hasta donde nos permitiera la censura» (Castellet, 1987: 46-47).

En I965 Castellet lanzó las colecciones «El Balancí», mayoritariamente de traducciones de novelística contemporánea extranjera, y «Biblioteca Bàsica de Cultura Contemporània», de clásicos del pensamiento contemporáneo, e intensificó la producción de la emblemática colección de ensayo "Llibres a l'Abast», fundada en 1962 e inspirada, en sus inicios, en la colección francesa «Que Sais-je», de las Presses Universitaires de France, de la cual se tradujeron algunos títulos. Aparte de estas tres colecciones que marcaron la historia de la incorporación de la literatura extranjera en Edicions 62, Castellet impulsó dos colecciones para un público más concreto: la de narrativa juvenil «E1 Trapezi» $\mathrm{y}$ 
la de novela policiaca «La Cua de Pall». Entre los orígenes de la editorial y ı969, las tres colecciones de novelística, «El Balancí», «El Trapezi» y «La Cua de Palla» sumaron I37 obras extranjeras traducidas de autores y autoras contemporáneas; por otro lado, «Llibres a l'Abast»y «Biblioteca Bàsica de Cultura Contemporània», 74 ensayos traducidos de temática variada: economía, filosofía, sociología, política, arte, historia, psicología, literatura, música y cine, entre otras disciplinas. A partir de I970, coincidiendo con una crisis económica, unida a la aventura ruinosa que significó Enciclopèdia Catalana, las cosas cambiaron drásticamente en Edicions 62, que se vio obligada a retardar la producción y, por lo tanto, disminuir notablemente las traducciones en sus colecciones.

En tanto que «mediador cultural hispánico», según palabras de Llanas (2015), en I965 Castellet también asumió la dirección literaria de Ediciones Península, la marca castellana de Edicions 62. Península fue un proyecto inicial de los fundadores Max Cahner y Ramon Bastardes que anhelaban «gracias a la existencia de un mercado más amplio, contribuir a la financiación de la empresa», a la vez que «ofrecer al mercado la versión castellana de obras catalanas o publicar libros que tratasen de temas de interés común a las dos culturas» (Muñoz, 2006: I77). En manos de Castellet, Península se convirtió en un sello de ensayo respetado. Se inició con la colección «Ibérica» y le siguió la prestigiosa colección «Historia/Ciencia/Sociedad» que, con más de 50 títulos en I969 de ensayistas españoles y extranjeros, clásicos y modernos, se convirtió en una colección de referencia en el panorama académico español del momento.

«Un director literario necesita, por más ojos, nariz, orejas y tacto que tenga, de las ideas de todo el mundo» (I987: 47), aseveraba Castellet en relación a la importancia del capital humano, intelectuales amigos y conocidos, en el nacimiento y posterior crecimiento de los catálogos de Edicions 62 y Península. "Yo creo que una de las cosas importantes de un editor es no querer hacerlo todo sino colaborar con asesores competentes» (Muñoz, 2006: 265), reafirmaba alabando el protagonismo de los colaboradores internos y externos que le acompañaron durante la concreción de las colecciones y la selección de sus autores y títulos. Cabe destacar que, durante esta época, Castellet empleó «muchos de los personajes que, siempre por motivos políticos, pasaban momentos de dificultad» (Muñoz, 2006: I78). Entre ellos, destacan nombres como el del político y uno de los padres de la constitución de 1978, Jordi Solé Tura, quien, entre I965 y I970, tradujo, siempre para Edicions 62 y para sustentarse económicamente, una trentena de obras de pensadores afines a su ideología marxista, o el del ingeniero industrial e ideólogo comunista, Alfonso Comín, quien, recién llegado de Málaga y sin trabajo, entre i965 y I967 fue reclutado para asesorar las colecciones de Península.

Desde Edicions 62 y Península, Castellet luchó para importar autores y títulos del pensamiento y la literatura universales. Desde su condición de intelectual polifacético, se esforzó por introducir corrientes estéticas, filosóficas e ideológicas, como el existencialismo, el marxismo, el estructuralismo y el feminismo, con el objetivo de modernizar un país condenado al ostracismo desde i939. Castellet ejerció un patrocinio irrepetible en un sistema literario necesitado de nuevas ideas al margen de la esfera política del momento. En los últimos años de la dictadura franquista, desde diferentes colecciones, Castellet impulsó traducciones de autoras feministas. A continuación, examinaremos, cómo introdujo algunos títulos de estas autoras y, de qué manera, por el hecho de haber «editado 
El segon sexe, de Simone de Beauvoir; La mística de la feminitat, de Betty Friedan, y La dona a Catalunya, encargo que había hecho a Maria Aurèlia Capmany», se acabó convirtiendo en un «interlocutor de esta cuestión» (20I2: I9I), como él mismo admitía en su espléndido retrato de la escritora Montserrat Roig.

\section{SIMONE DE BEAUVOIR}

\section{Y LE DEUXİ̀ME SEXE}

A finales de i949, Josep Maria Castellet publicó una reseña de Le deuxième sexe en la revista profalangista Estilo, que enfureció al obispo de Barcelona Gregorio Modrego. En la biografía Josep Maria Castellet. Retrat de personatge en grup (2006), Teresa Lloret reúne las epístolas donde Castellet lo denunciaba a su amigo Joan Ferraté:

Barcelona, I4 diciembre I949. Estilo. Su Ilustrísima Padre Modrego Obispo de Barcelona ha prohibido el último número de la revista. Las autoridades competentes han ordenado la recogida del número de la revista. Y todo por un inocente artículo mío, completamente «inocuo» pero que les ha resultado diabólico. El artículo era un comentario al libro de Simone de Beauvoir, Le deuxième sexe. Si puedo conseguir algún ejemplar te lo enviaré, no porque pueda interesarte el artículo sino porque veas el grado de extrema tontería a la que han llegado todas las clases dominadoras. Previamente, para los números I y 2 de la revista, el obispo ya había llamado al jefe del SEU para avisarle de que en la revista había un núcleo -Pocholo y yo- peligroso. Esta tarde «por orden superior» han clausurado el local de la revista. Bien está lo que bien acaba.

Por este y otros motivos han destituido el jefe del seu. Mientras se aclara la situación -de maravillosos detalles de pequeña política, ambiciones estrechas, etc.- el Cine-Club también está clausurado y yo a punto de excomunión. [...]
Barcelona, 22 diciembre I949. Sigo asediado por el obispo. Su Ilustrísima, todo acojonado porque en su diócesis se publican marranadas como mi artículo, dio el «chivatazo» al gobernador y este buen hombre ha dado orden de que se haga una intervención sobre la trayectoria vital e intelectual de Pocholo y la mía. Sospechan que detrás nuestro se mueva un grupo -masones, comunistas, catalanistas o, simplemente, correistas ${ }^{4}$ del cual nosotros somos los hombres de paja. Están locos. [...]

Barcelona, I4 de enero 1950. Las cosas han mejorado mucho [...] el obispo, a través de Pocholo que le visitó, nos dio a todos los «réprobos» su episcopal o santísima bendición. Por lo tanto estoy todo purificado y me siento otro hombre.

Dos frases del obispo a Pocholo: «...yo sé que vosotros sois unos buenos chicos, pero la 'torre de marfil' del $\mathrm{n}^{\circ} 2$ es de un claro relativismo kantiano». "... y a mí nadie me podrá negar que el artículo de Le deuxième sexe es francamente pornográfico». Tenías razón: un obispo que es obispo y aragonés tiene que tener una descomunal burricia. (Lloret, 2006: 56)

Ante tal atentado a los pilares morales de la iglesia franquista, Gregorio Modrego exigió al gobernador civil, Eduardo Baeza Alegría, retirar el número de la revista, cerrarla temporalmente y despachar al autor por ser sospechoso de actividades subversivas contra el régimen. Con sus amigos intelectuales, entre ellos el citado Pocholo (Jesús Nuñez, del grupo del Instituto Balmes, colaborador también de las revistas Estilo y Laye), se vinculaba a Castellet a algún tipo de grupo subversivo no determinado, como los «masones, comunistas, catalanistas o, simplemente, correistas» (Lloret, 2006: 56).

4 Recordemos que los «correistas» eran los seguidores del gobernador Antonio Correa Véglison, militar y, entre I940 y I945, gobernador civil de Barcelona. Durante su mandato autorizó restringidamente las sardanas y la publicación, en ortografía prefabriana, de las obras completas de Jacint Verdaguer. En 1945 fue destituido y sustituido por Bartolomé Barba Hernández. 
En la España de los años cincuenta, las revistas del Sindicato Español Universitario (SEU), al cual estaban afiliados todos los estudiantes, facilitaban una plataforma para expresarse más o menos oficialmente. En tanto que revistas del Movimiento, no pasaban por censura previa, cosa que auguraba que tenían una vida corta y que era habitual cerrarlas, reabrirlas o expulsar a sus colaboradores, cuando algún alto cargo eclesiástico o gubernamental denunciaba el contenido de sus artículos. Obviamente Castellet conocía el talante de Estilo, como se puede observar en otra carta a Joan Ferreté, del I7 de enero de I949: «Te envío Estilo -espectáculo repugnante, presentación infame, contenido vomitivo- para que veas, conozcas y abjures una vez más del SEU, de la Universidad, de nosotros, universitarios» (Lloret, 2006: 54).

Después de Estilo, colaboró en la revista Laye, nacida en marzo de I950 como boletín cultural destinado a los doctores y licenciados de Cataluña y Baleares. Muchos de los colaboradores universitarios de estas dos revistas acabaron convirtiéndose en miembros de la Escuela de Barcelona, de la cual destacan nombres como los de Carlos Barral, Alfonso Costafreda, Jaime Ferrán, Jaime Gil de Biedma, José Agustín Goytisolo, José Sacristán o el mismo Castellet. En esa época sus lecturas preferidas eran los escritores existencialistas, marxistas, realistas y estructuralistas. Y uno de los más adorados por el grupo fue Jean-Paul Sartre. Cabe hacer hincapié que Castellet llegó a Simone de Beauvoir a través de Sartre. Castellet fue uno de los promotores más implicados del filósofo francés en España durante la dictadura franquista. 5 Desde I950 hasta al final de sus días, difundió sus ideas

5 Para conocer la recepción de Sartre en España y su relación con Castellet, se pueden consultar, entre otros, los estudios de Castellet (1973), Marsal (r979), Van Lawick (1988), Broch (1996) y Vall (2000). 
formarse en un ambiente de amplitud, de libertad intelectual y moral que repercute de un modo decisivo en la formación de su vida interna y de su vida cultural. No sucede así en España. Confesamos que lo que nos ha impresionado más del libro de Simone de Beauvoir no ha sido su contenido sino la constatación inconsciente que íbamos haciendo a medida que avanzábamos por sus páginas de lo lejana que quedaba la mujer española actual, de un problema tan interesante y decisivo para ella como este de su limitación y libertad. (Castellet, I949: 8)

También se refería a la carencia de libertad del régimen de Franco y a la censura: «Hoy por hoy, ahora, finalizado el año 1949, la mujer está apartada totalmente de la vida pública española como lo está de su vida intelectual y cultural. ¿Las causas? Es difícil averiguarlas y una vez conocidas, es posible que sea mejor callarlas» (I949: 8). Cerraba la reseña abordando una cuestión tabú para la época, la prostitución en España: "Que a mano tenemos las estadísticas de prostitución en España, capaces de hacer palidecer a las que citábamos antes del aborto en Francia» (1949: 9). No es extraño que denunciar la situación de la mujer en España, reivindicar su participación en la vida pública y defender a una sospechosa atea, marxista y feminista como Simone de Beauvoir le reportara, a finales de los años cuarenta, una seria represalia. Castellet esperó veinte años y, cuando llegó la ocasión, luchó por recuperar el tiempo perdido y ofrecer obras de Beauvoir al público catalán. Obviamente, empezó por Le deuxième sexe.

Con un retraso considerable (diecinueve años después de la publicación del original en París, dieciséis después de la traducción inglesa y catorce después de la española argentina), y a pesar de los múltiples agravios censores, Simone de Beauvoir llegó por primera vez a España en catalán, aunque la mayoría de sus obras ya esta- ban traducidas en Argentina. Psique publicó la traducción de El segundo sexo en 1954, a cargo de Pablo Palant, e intentó importarla a España en I955. No obstante, el MIT lo denegó. Recordemos que en ese momento algunos filósofos eran traducidos antes al catalán que al castellano (Marx, Gramsci, Sartre, Camus, Marcuse, etc.). Prohibidos desde siempre por el franquismo, los editores de América Latina habían comprado los derechos de reproducción al español (Vallverdú, 20I3).

Por lo tanto, la primera solicitud de autorización para traducir al catalán una obra de Beauvoir que se presentó al MIT fue la de $E l$ segon sexe. Sin embargo, entregada a trámite la solicitud el 7 de abril de I965, el libro no llegó a las librerías hasta junio de i968, casi tres años después, cuando ya existían cuatro traducciones catalanas publicadas de la autora (Godayol 20r3a). En el Archivo General de la Administración, de Alcalá de Henares, hay dos expedientes de censura de la traducción catalana de El segon sexe. El primero, de 1965, concluye con la denegación de la solicitud y la subsiguiente denegación del recurso de revisión. E1 segundo, de 1967 , finaliza con la autorización de la traducción el 20 de junio de ig68. En «Censure, féminisme et traduction: Le deuxième sexe de Simone de Beauvoir en catalan» (Godayol, 20I3b) dimos a conocer los expedientes abiertos a la traducción catalana de Le deuxième sexe, con la finalidad de mostrar las múltiples coyunturas que experimentó la obra antes de salir a la luz. Aunque la traducción fue finalmente autorizada, el MIT inventó todo tipo de trabas para no hacer avanzar el expediente. Sin embargo, llegó un momento que la notoriedad internacional de la autora, la especialización temática y el tiraje reducido favorecieron que se aprobaran sus traducciones, siempre con la condición de que 
se ejecutaran las tachaduras convenidas por los censores.

Como muchos editores de estos años, Cas- tellet siempre mantuvo una lucha encarnizada contra la censura. Se encargaba personalmente de las visitas al MIT. Desde el inicio de Edicions 62, sus directivos «habían decidido que recurrirían sistemáticamente contra cualquier decisión censora, tanto si se trataba de una prohibición como de tachaduras de fragmentos» (Muñoz, 2006: I79). Por lo tanto, Castellet hizo muchos viajes a Madrid para negociar y renegociar desautorizaciones y autorizaciones condicionadas. Cabe destacar que, a diferencia de la Ley de Prensa de 1938, que forzaba todos los libros a pasar por censura obligatoria, la Ley de Prensa y de Imprenta del i8 de marzo de I966, la llamada Ley Fraga, dejaba escoger entre presentar la solicitud antes de empezar la producción, como la ley anterior, o hacerlo después depositando seis ejemplares ya impresos en los organismos censores para ser revisados. Edicions 62 no pudo escoger entre la primera y la segunda opción. La causa fue que la Ley de 1966 exigía a las editoriales inscribirse en un registro editorial del MIT y, en el caso de editoriales marcadamente ideológicas, se les denegó el preceptivo número de registro. Después de muchas gestiones, Edicions 62 lo obtuvo en I973. En consecuencia, esta arbitrariedad administrativa requirió a Castellet muchas reuniones con los ejecutivos del MIT, tanto con simples funcionarios como con sus jefes.

En sus «Memòries poc formals d'un director literari», Castellet narra algunas anécdotas vividas en los despachos y subterráneos de aquellas oficinas. Sobre las negociaciones con el entonces funcionario responsable de la censura, afirmaba: "Yo intentaba convencer a Faustino Sánchez-Marín que nuestros libros eran 'inocentes'. Nunca me dejaba ganar de manera apreciable. Salvabas un libro u otro, con algunas tachaduras inocuas, y volvías contento». Con frustración, añadía: «La sensación de indignación era absoluta: hablar con aquella gente era lo mismo que tratar con la policía política. Toda conversación era una degradación moral absoluta» (1987: 38). Asimismo, remarca que el trato con los directores generales era aún más «hipócrita»: «Robles Piquer me recibió un día y me dijo: ‘QQué le hemos hecho ahora? Vamos a resolverlo enseguida.' Resolvimos lo mismo que resolvíamos en el subterráneo donde despachábamos con Sánchez-Marín. Cuatro tachaduras y un libro milagrosamente salvado gracias a su generosidad» (1987: 38). Castellet también explica que muchos de estos viajes a Madrid los hacía con Alfonso Comín, de Península, y otros directores literarios de Barcelona: «la cosa era tan aburrida y siniestra que nos hacía falta compañía» (1987: 38).

Después de múltiples idas y venidas a la capital, en I968, conseguido el esperado permiso del MIT, Castellet encargó la traducción de El segon sexe a Hermínia Grau y Carme Vilaginés (Bacardí y Godayol, 2orr). El prólogo fue confiado a la novelista y ensayista Maria Aurèlia Capmany, convertida en ese momento en la «feminista nacional», como la bautizó más tarde Teresa Pàmies (I983: I2). El texto de Capmany deja entrever que la situación de la mujer empieza a cambiar y que las jóvenes, que no han vivido la Guerra Civil, miran el futuro de otra manera. Las últimas líneas son paradigmáticas: «El segon sexe llega hoy, después de veinte años, a un nuevo clima: la aventura de esta traducción es la prueba. Una nueva juventud tiene tendencia a decir las cosas por su nombre y a no horripilarse» (I968: I8). 


\section{BETTY FRIEDAN Y THE FEMININE MYSTIQUE}

Aconsejado o por iniciativa propia, Josep Maria Castellet fue el promotor directo de la versión al catalán de The feminine mystique. Agustí Pons lo hace evidente en su biografía de Maria Aurèlia Capmany: «En Cataluña, el olfato editorial de Josep Maria Castellet hizo posible que ya en el año I965 se publicara una traducción al catalán -La mística de la feminitat- del libro de Betty Friedan» (2000: 244). Al editor le pareció una inversión intelectual. Siendo consciente de que la situación política, jurídica, económica y social de la mujer americana no tenía nada que ver con la de la mujer española, Castellet intuyó que el libro podía ser rentable por, al menos, dos fundamentos: el social y el económico. Por un lado, ante el cambio de mentalidad impulsado por algunos tecnócratas del régimen franquista, los nuevos tiempos requerían temas novedosos, inclusive los femeninos. Por el otro, originariamente publicado en 1963, The feminine mystique había sido un auténtico bestseller en Estados Unidos, que había superado los tres millones de ejemplares vendidos.

Edicions 62 entregó al MIT la solicitud de traducción al catalán de The feminine mystique el ig de febrero de 1965, quince días antes que la de Le deuxième sexe. Como era habitual, se solicitaron dos informes de lectura. El primero al padre Saturnino Álvarez Turienzo y el segundo al padre Miguel Oromí Inglés. Recordemos que, en líneas generales, había dos perfiles de censores: los más intelectuales, que incluían miembros de la iglesia, militares activos o en reserva y académicos, y los funcionarios. En el caso de Friedan, se adjudicaron a dos religiosos de confianza de las altas esferas franquistas, que, días más tarde, también fueron dos de los seis censores de Le deuxième sexe. A diferencia del clásico de Beauvoir, el de Friedan no se fiscalizó tan rotundamente $y$, con algunas tachaduras, obtuvo la autorización el i3 de septiembre de 1965, siete meses después de enviar la solicitud. Con pocos meses de diferencia, la editorial Sagitario, de Barcelona, también tradujo al castellano el mismo título. Tampoco tuvo ningún problema administrativo para obtener el permiso de traducción. En «Feminism and translation in the sixties: the reception in Catalunya of Betty Friedan's The feminine mystique» (Godayol, 20I4), estudiamos las dos versiones y el hecho de ser avaladas por dos embajadoras opuestas del mundo de la cultura: en el caso catalán, Maria Aurèlia Capmany, y, en el castellano, la deportista y escritora católica Lilí Álvarez, condesa de la Valdene.

Obtenido el permiso del MIT con pronta diligencia, Castellet encargó al amigo Jordi Solé-Tura, la traducción, que se publicó en dos volúmenes en la colección de «Llibres a l'Abast» (Bacardí y Godayol, 2oII). Sin gozar de un movimiento feminista emprendedor como el anglosajón, la publicación de La mistica de la feminitat caló suavemente en la sociedad catalana. Advertido el éxito, Castellet consideró que sería beneficioso impulsar, desde la misma colección, una «adaptación» que estudiase la coyuntura de la mujer en Cataluña. Colaboradora y traductora habitual de Edicions 62, escogió a Capmany para este cometido. La dona a Catalunya. Consciència i situació se publicó en abril de I966. Constituyó, según Lluïsa Julià (2002: 120), «la primera historia moderna del feminismo y de la situación de la mujer» en Cataluña. «Salvando las debidas distancias», el encargo de Castellet elaborado por Campany, «provocó un impacto parecido al de The feminine mystique en los Estados Unidos» (Pons, 2000: 248). Después de prolongados años de silencio androcéntrico y leyes discriminatorias, 
el debate sobre el papel social de la mujer irrumpía con fuerza, obviamente dentro de los límites políticos del momento. Capmany se convirtió en referente de los supuestos feministas. Entre los muchos libros que publicó sobre el tema, destacan otros dos: El feminismo ibérico (I970), escrito en colaboración con Carmen Alcalde, y El feminisme a Catalunya (1973).

\section{MARY MCCARTHY Y THE COMPANY SHE KEEPS}

Mary McCarthy y Josep Maria Castellet se conocieron un I5 de octubre de r963 en el Hotel Suecia de Madrid, donde se celebró el seminario «Realismo y realidad en la literatura contemporánea», organizado por José Luis Aranguren, con la ayuda de otros intelectuales como el mismo Castellet, que defendían el realismo social en la literatura. El certamen se vio envuelto en la controversia de boicotear o no el acto en defensa de "La carta de los Io2» contra las torturas de los mineros de Asturias, firmada por los mismos intelectuales y dirigida al entonces ministro Manuel Fraga Iribarne, que había calificado de falsos e inexactos los hechos denunciados. A pesar de la extrema crispación política de aquellos días, Aranguren optó por seguir adelante. Finalmente, el acto se celebró y reunió una nómina insólita de intelectuales extranjeros y nacionales, desde Jean Bloch-Michel, Nicola Chiaromonte, Pierre Emmanuel, Mary McCarthy, Nathalie Sarraute o Jean Starobinski, hasta Gonzalo Torrente Ballester, Consuelo Berges, Miguel Delibes, Fernando Morán, Joan Oliver, Joan Triadú, Francesc Vallverdú, etc. (invitados Italo Calvino y Elio Vittorini, decidieron no asistir en solidaridad con Giulio Einaudi, a quien se le había prohibido entrar en el país). Años más tarde, Castellet situaba «la crisis del realismo alrede- dor de este seminario» (I988: 237) y admitía que el encuentro le había sumergido en una depresión intelectual, no política. Aseguraba que «La gracia del seminario fue la de dar acto de fe de una batalla perdida de antemano» (I988: 236). Y concluía: «Éramos kamikazes que queríamos que se reconociera, desde el exterior, el sentido de una situación imposible entre la voluntad de creación literaria libre y la penosa, aburrida y cotidiana aberración de la censura» (I988: 236).

Veinticinco años después, en Els escenaris de la memoria (I988), libro de retratos literarios de "grandes actores de la farándula literaria que he conocido» (I988: II) (Giuseppe Ungaretti, Mercè Rodoreda, Rafael Alberti, Josep Pla, Pier Paolo Pasolini, Octavio Paz, José Luis Aranguren, Mary McCarthy y Pere Gimferrer), Castellet dedicó un magnífico capítulo a Mary McCarthy y a su estancia en el convulso seminario madrileño, y justificó la elección de escribir sobre la autora norteamericana «porque fue con ella con quien mantuve las conversaciones más largas y amenas de todos los extranjeros» (I988: 237).

Relativamente distinguido, con un restaurante notable y un bar discreto, el Hotel Suecia fue la sede central del seminario. En ese momento, también era el cuartel general de Carlos Barral cuando se trasladaba a Madrid por cuestiones editoriales y el de «sus poulains» y «editores amigos cuando iban a discutir con los censores» (1988: 238). Por lo tanto, el emplazamiento se había convertido en un lugar de encuentro amable y concurrido entre autores, editores y políticos medio clandestinos. Mary McCarthy y Josep Maria Castellet coincidieron en la ponencia de Castellet, una de las cinco que se impartieron. A cada ponencia le seguía un comentario de uno de los autores invitados. A Castellet le tocó Mary McCarthy, quien, sentada a su lado, «con ganas de hablar francamente», "provocati- 
vamente», «con charme», dedicó su intervención a ir «contra el realismo practicado por buena parte de los asistentes» (I988: 235), hecho que indignó a algunos, que la etiquetaron de «reaccionaria yanqui al servicio de la CIA» (I988: 236).

Cuando coincidieron por primera vez en Madrid, la escritora tenía cincuenta años y el editor treinta y seis. Al editor le impresionó el rostro de $\mathrm{McC}$ arthy, «ligeramente duro, con rasgos ligeramente viriles, pero muy atractivos» (I988: 225), así como su feminismo críticamente militante y su compromiso social reaccionario, «a la manera de los 'liberales' americanos» (I988: 227). Después de la ponencia, charlaron amigablemente durante horas en el bar del hotel sobre su biografía, el mito de ser «una vassar», ${ }^{6}$ la situación de los escritores en España y su militancia política, etc. Más tarde, entre 1964 i 1966 , se vieron fugazmente unas pocas veces en París. «Risueña, muy franca de expresión, provocativa en sus comentarios» (I988: 23I), el personaje caló profundamente en Castellet. En el marco del coloquio que "firmaría la defunción del realismo» (I988: 247), Mary McCarthy, «una distinguida señora de Vassar College, un poco descarriada a la izquierda» (1988: 247), fue uno de los mejores recuerdos e incentivos intelectuales de aquel momento.

Después de conocerla, Castellet desvela, en este mismo retrato, que intentó conseguir el permiso del MIT para traducir The group (1963), la reciente y ya famosa novela sobre la vida de ocho amigas después de graduarse en Vassar College, pero que «obstinadamente, la censura franquista, no sé porqué, se negó a dar el visto bueno» (I988: 229). No desistió y buscó otra obra. Edicions 62 presentó la solicitud para traducir al catalán The company she keeps, de Mary

6 Creado en r86I, el año de la envestidura de Abraham Lincoln, Vassar College fue el primer colegio universitario femenino y feminista de los Estados Unidos.
McCarthy, el 9 de diciembre de 1967. El MIT la devolvió el 20 de diciembre, firmada por el censor Antonio Albizu, autorizándola con algunas tachaduras referentes a descripciones de relaciones sexuales. Tres meses después, el 29 de marzo de r 1969 , se presentó de nuevo con los cambios requeridos, y fue revisada por otro censor bien considerado por las altas esferas franquistas, Francisco Fernández Jardón, quien la autorizó el I8 de abril de i969 con una tachadura de orden político: la palabra «democracia» debía ser sustituida por la de «república».7 Finalmente, presentada de nuevo, se autorizaba el 2I de octubre de 1969. Con el permiso del MIT, se encargó la traducción al escritor y prolífico traductor del inglés y el francés Ramon Folch i Camarasa (Barcelona, 1926), el cual, como otros intelectuales, en esa época vivía de la traducción, trabajando, mayoritariamente, para Edicions 62 y Nova Terra (Bacardí y Godayol, 20II).

\section{CONCLUSIONES: «LA ESPONJOSIDAD» DE JOSEP MARIA CASTELLET}

El mecenazgo está formado por tres elementos que interaccionan según varias combinaciones. Hay un componente ideológico que actúa como constricción a la hora de elegir y desarrollar la forma y el tema. [...] Existe también un componente económico: el mecenas se ocupa de que los escritores y reescritores puedan vivir, dándoles una subvención o un puesto de trabajo. [...] Finalmente, también hay una cuestión de estatus. La aceptación del mecenazgo implica la integración en un determinado grupo y su estilo de vida. (Lefevere, 1997: 30-31; traducción de M. Carmen África Vidal y Román Álvarez).

7 Párrafo manuscrito de Francisco Fernández Jardón escrito al margen del informe de lectura mecanoscrito por Antonio Albizu, fechado en Madrid, el 20 de diciembre de I967 (AGA 2I-I86Io, expediente 09976). 
Josep Maria Castellet integra, con más o menos constricciones sociales y políticas, los tres factores que Lefevere describe que interaccionan en los mecenazgos. Operando desde los márgenes de un sistema literario desnaturalizado por más de dos décadas de dictadura, desde su cargo de director literario de Edicions 62 y Península, y con la ambición de construir unos sellos editoriales al nivel de los europeos -como Einaudi, Feltrinelli, Gallimard o Suhrkamp-, Castellet ejerció un ambicioso mecenazgo de contrapeso de la ortodoxia reinante, con el objetivo de insertar en el sistema social de los últimos lustros del franquismo un subsistema literario crítico y abierto a las tendencias extranjeras. En concreto, a través de la creación de nuevas colecciones y la incentivación de otras, promocionó obras y autores marcadamente ideológicos, que a su vez crearon un canon paralelo de textos no cómplices del discurso nacional-católico dominante. Ante la orfandad literaria paterna y materna que había incentivado el franquismo, Castellet viajó, asistió a encuentros con editores y autores, conversó con ellos y se dejó aconsejar sobre nombres y títulos para confeccionar unas colecciones a la altura de las de las editoriales internacionales. Asimismo, desde su posición privilegiada de editor, contrató a amigos y conocidos intelectuales antifranquistas, gracias a lo cual pudieron mantenerse y a la vez dedicarse a la escritura. Supo lidiar magistralmente con la época histórica. Se encargó personalmente de las visitas a los despachos de los censores del MIT e intentó hacerles comprender, con relativos éxitos y muchas negativas, que «nuestra sociedad perteneciente al mundo occidental nos obligaba a un cierto liberalismo» (I988: 38 ).

Cuando a Castellet se le preguntaba por las facultades que debía tener un director literario,

siempre destacaba como prioritaria la «esponjosidad»:

Las radiografías de los cerebros de los directores literarios más competentes tienden a parecerse a una esponja de mar, es decir, una esponja de verdad. La esponja absorbe las sensaciones visuales, olfativas, sonoras y táctiles de todo lo que llevamos dicho. A continuación, después de una contracción, ha de expeler todas estas sensaciones en forma de idea de libro posible y realizable, si puede ser de éxito o, si acaso, de prestigio. (I988: 3I)

Además de la curiosidad, la lucidez, la sagacidad y la flexibilidad, también subrayaba «el savoir faire, el trato social» (I988: 3I). A Castellet le interesaba la obra, pero también la persona que había detrás del autor. Castellet se relacionó con muchos que publicaron en Edicions 62. En el caso de Mary McCarthy, desde su encuentro en Madrid, la mitificó y anheló gozar de su confianza: «Nunca pude establecer con ella una amistad profunda del tipo de las que ella y Hannah Arendt preconizaban» (1988: 247). Si McCarthy se convirtió en una quimera, Simone de Beauvoir fue una obsesión, que aumentaba día a día a medida que la censura vetaba sus escritos. Obviamente Castellet también publicó las tres autoras estudiadas aquí, Friedan sobre todo, con fines comerciales. Pero, sea como fuere, el editor de trato exquisito propició la llegada de «madres simbólicas extranjeras» en un momento en que faltaban modelos en los incipientes discursos feministas del país. Como el mismo título de su libro de retratos de seis grandes amigos (Manuel Sacristán, Carlos Barral, Gabriel Ferrater, Joan Fuster, Alfonso Comín y Terenci Moix), Josep Maria Castellet fue un editor «seductor, ilustrado y visionario». 
RECIBIDO EN FEBRERO DE 2015

ACEPTADO EN JULIO DE 2015

VERSIÓN FINAL DE SEPTIEMBRE DE 2015

\section{REFERENCIAS BIBLIOGRÁFICAS}

Abellán M.L. (1980). Censura y creación literaria en España (1939-I976), Barcelona: Península.

Alcalde, C.; Capmany, M.A. (I970). El feminismo ibérico. Barcelona: Tau.

Bacardí, M., 20I2. La traducció catalana sota el franquisme, Lleida: Punctum.

Bacardí, M.; Godayol, P. (eds.) (20II). Diccionari de la traducció catalana, Vic: UAB, UIB, UJI, UVic y Eumo Editorial.

Barral, C. (200I). Memorias, Barcelona: Península.

Beauvoir, S. de (I968). El segon sexe, Barcelona: Editorial 62. (Trad. H. Grau y C. Vilaginés)

Broch, À. (1996). «Un intel-lectual sartrià». En: Homenatge a J.M. Castellet. Barcelona: Edicions, 62. pp. $4 \mathrm{I}-45$.

Capmany, M.A. (I968). «Pròleg». En: S. de Beauvoir. El segon sexe, Barcelona: Editorial 62. pp. 5-18. (Trad. H. Grau y C. Vilaginés) (I966). La dona a Catalunya. Consciència i situación, Barcelona: Edicions 62. (I973). El feminisme a Catalunya, Barcelona: Nova Terra.

Castellet, J.M. (1949). «Le deuxième sexe». Estilo, 5 diciembre, pp. 8-9.

(I955). Notas sobre literatura española contemporánea, Barcelona: Seix Barral.

(1957). La hora del lector. Notas para la iniciación a la literatura narrativa de nuestros días, Barcelona: Seix Barral.

(I960). Veinte años de poesía española. Antología de la poesía española de 1939-1959, Barcelona: Seix Barral. (1973). Dietari de 1973, Barcelona: Edicions 62. (1976). Literatura, ideología y política, Barcelona: Anagrama. (I987). "Memòries poc formals d'un editor literari». En: Edicions 62. Vint-i-cinc anys (1962-I987), Barcelona: Edicions 62.

(I988). Els escenaris de la memoria, Barcelona: Edicions 62.
(2009). Seductors, il-lustrats $i$ visionaris. Sis personatges en temps adversos, Barcelona: Edicions 62. (2012). Memòries confidencials d'un editor. Tres escriptors amics, Barcelona: Edicions 62.

Cisquella, G. et al. (1977). La represión cultural en el franquismo. Diez años de censura de libros durante la Ley de Prensa (1966-1976), Barcelona: Anagrama.

Cornellà-Detrell, J. (20I0). «Traducció i censura en la represa cultural dels anys i960». L'Avenç 359, p.44-5I.

Friedan, B. (1965). La mística de la feminitat. Barcelona: Edicions 62. (Trad. J. Solé-Tura).

Godayol, P. (2013a). «Simone de Beauvoir en català». Bulletin Hispanique, $\mathrm{II5} / 2$, pp. 669-684.

(2013b). «Censure, féminisme et traduction: Le deuxième sexe de Simone de Beauvoir en catalan». Nouvelles Questions Féministes, 32/2, pp. 74-89. (20I4). «Feminism and translation in the I96os: the reception in Catalunya of Betty Friedan's The Feminine Mystique». Translation Studies, 7/3, pp. 267-213.

(2015). «The Francoist censorship and the Catalan translations of Jean-Paul Sartre». Perspectives. Studies in Translatology. (in press)

Gutiérrez-Lanza, C. (I997). «Leyes y criterios de censura en la España Franquista: Tradución y recepción de textos literarios». En: M.A. Vega y R. Martín-Gaitero (eds.), La palabra vertida. Investigaciones en torno a la Traducción, Madrid: Editorial Complutense. pp. 283-29o.

Julià, L1. (2002). «Les nostres intel·lectuals: Maria Aurèlia Capmany i Montserrat Roig». En: M. Palau y R.D. Martínez Gili (eds.), Maria Aurèlia Capmany: l'afirmació en la paraula. Valls: Cossetània. pp. II7-I3O.

Lefevere, A. (1997). Traducción, reescritura y la manipulación del canon literario, Salamanca: Ediciones Colegio de España. (Trad. M.C.Á. Vidal y R. Álvarez).

Llanas, M. (2006). L'edició a Catalunya: el segle XX (I939-I975), Barcelona: Gremi d'Editors de Catalunya.

(2007). L'edició a Catalunya: el segle XX (els darrers trenta anys), Barcelona: Gremi d'Editors de Catalunya.

(2015). «Josep Maria Castellet: aspects, criteris i idees d'un director literari». En: E. Gallén (ed.), Josep Maria castellet, editor i mediador cultural. (in press) 
Lawick, H. van (I988). «Heike van Lawick entrevista Josep Maria Castellet». Daina, 5 (noviembre), pp. - $23 .^{-23}$

Marsal, J.F. (1979). Pensar bajo el franquismo. Intelectuales y politica en la generación de los años cincuenta, Barcelona: Península.

McCarthy, M. (I969). Aparadors per a una dona, Barcelona: Edicions 62. (Trad. R. Folch i Caramasa)

Muñoz Lloret, T. (2005). «Josep Maria Castellet, l'escepticisme combatiu». L'Avenç, 300 (marzo), pp. $57^{-63}$.

(2006). Josep Maria Castellet. Retrat de personatge en grup, Barcelona: Edicions 62.
Pàmies, T. (1976). Maig de les dones. Crònica d'unes Jornades, Barcelona: Laia.

Pons, A. (2000). Maria Aurèlia Capmany. Lèpoca d'una dona, Barcelona: Columna.

Riera, C. (1988). La Escuela de Barcelona, Barcelona: Anagrama.

Vall, X. (2000). "Josep Maria Castellet i 'l'existencialisme'». Els Marges, 66, pp. 7-23.

Vallverdú, F. (1987). «L'edició en català i l'experiènc ia d'Edicions 62». En: Edicions 62. Vint-i-cinc anys (1962-1987), Barcelona: Edicions 62.

(2013). «La traducció i la censura franquista: la meva experiència a Edicions 62». Quaderns. Revista de Traducció, 20, pp. 9-16. 